\title{
EL COMPLEJO ARQUITECTÓNICO DE LA PIRÁMIDE DEL SOL EN TEOTIHUACÁN, VESTIGIOS DE CULTO Y ADORACIÓN
}

\section{THE ARCHITECTURAL COMPLEX OF THE PYRAMID OF THE SUN IN TEOTIHUACÁN, VESTIGES OF WORSHIP AND ADORATION}

\author{
Alejandro Sarabia González ${ }^{1}$ \\ sarabiaalejandro@hotmail.com \\ Nelly Zoé Núñez Rendón ${ }^{2}$ \\ nellyzoe75@hotmail.com
}

\section{RESUMEN}

Una de las ciudades antiguas reconocida por su traza urbana y desarrollo constructivo es Teotihuacán. En este valle se desarrolló una sociedad compleja que además de cubrir sus necesidades básicas, también desarrollaron gran maestría escultórica, pictórica y de objetos utilitarios por mencionar algunos. Uno de los temas que abordaremos es el uso ritual de esculturas encontradas en el complejo arquitectónico de la pirámide del Sol, así como los indicios encontrados sobre la decoración que en algún momento tuvo este edificio prehispánico.

Palabras clave: arqueología, Teotihuacán, Mesoamérica.

\footnotetext{
${ }^{1}$ Director, Proyecto de conservación de la Pirámide del Sol, Instituto Nacional de Antropología y Historia - INAH, México.

${ }^{2}$ Investigadora, Proyecto Tlalocan, Instituto Nacional de Antropología y Historia - INAH, México.
} 


\section{ABSTRACT}

One of the ancient cities recognized for its urban layout and constructive development was Teotihuacán. In this valley, a complex society developed that, in addition to meeting their basic needs, also developed great mastery of sculpture, painting and utilitarian objects, to name a few. One of the topics that we will address is the ritual use of sculptures found in the architectural complex of the Pyramid of the Sun, as well as the indications found about the decoration that this pre-Hispanic building had at some point.

Keywords: archeology, Teotihuacán, Mesoamerica,

\section{Contexto de la investigación}

La Civilización de Mesoamérica tiene un desarrollo cultural que inicia en el segundo milenio antes de Cristo; para el 200 a C se han consolidado ampliamente una cultura general basada en la diversidad de ambientes naturales y un desarrollo tecnológico básico, permitiendo rasgos particulares de la cosmovisión y la materialización de la cultura, así como de las estructuras sociales, con bases generales comunes. Esta civilización contaba con un desarrollo cultural cada vez más acelerado y en donde surgen los asentamientos urbanos como nueva forma de vida, es el caso de Monte Albán, Cuicuilco, Teotihuacán, Cholula y varias otras ciudades, que contaron con aspectos formales que recuerdan los complejos olmecas de La Venta, Laguna de los Cerros, San Lorenzo Tenochtitlán y algunos otros; Aspectos culturales como los sistemas calendáricos, sistemas de escritura, sistemas numéricos, sistemas constructivos, tecnología agrícola, sistemas de gobierno, estructuras políticas y varios otros, contaran con bases comunes similares y diversificados en regiones y grupos culturales particulares. De esta manera los inicios de Teotihuacán fueron rápidos y concretos, en donde el 
movimiento poblacional de la cuenca de México tuvo un asentamiento principal y dominante políticamente.

El desarrollo de Teotihuacán como fenómeno cultural y específicamente urbano no puede desligarse del desarrollo cultural de Mesoamérica, si bien se considera como un foco máximo de desarrollo de la civilización Mesoamérica entre el siglo II y el siglo VI d C es sin duda una ciudad con una cosmovisión Mesoamericana. En esta oportunidad describimos el monumento más grande construido en Teotihuacán, es para su tiempo uno de los edificios más grandes construidos por el hombre, y sin embargo no es un edificio aislado en la cuidad antigua, forma parte de un patrón urbano, en donde la estructura urbana es el objetivo de la materialización de una cosmovisión particular de la Cuenca de México; la ciudad de Teotihuacán fue la ciudad y el asentamiento rector de la Cuenta de México. En su estructura urbana la ciudad antigua de Teotihuacán cuenta con un orden horizontal bien definido, en done la Calle de los Muertos es el eje de la ciudad con un rumbo de norte a sur, este orden desde su inicio en el siglo uno o dos DC refleja una rígida estructura social.

El centro urbano de la ciudad presenta las mayores construcciones, las cuales se distinguen por contar con plataformas que las delimita y aísla del resto de la ciudad, como una muralla, el caso mejor conocido es la Ciudadela, de la misma forma la Pirámide del Sol está claramente delimitada por una amplia muralla de $34 \mathrm{~m}$ de ancho, $350 \mathrm{~m}$ de largo y $6 \mathrm{~m}$ de altura, en donde el principal acceso es 
por una amplia escalinata desde la Calle de los Muertos, a este espacio arquitectónico o unidad urbana la definimos como Complejo Arquitectónico de la Pirámide del Sol (Sarabia 2016: 4-6); en donde la Pirámide del Sol y las tres plataformas adosadas a su fachada principal son la construcción principal, las dimensiones originales de la gran pirámide distan poco de las actuales, con $215 \mathrm{~m}$ por lado en su base, cerca de $70 \mathrm{~m}$ de altura y construida principalmente con arcilladas del valle, algunos paquetes de adobes, rocas y arenas, se construyo en un solo momento constructivo, logrando ser el edifico más grande de la ciudad desde su inicio. Son también tres plazas abiertas, una unidad residencial, una unidad administrativa y el adoratorio central de la plaza principal. Es importante entender que cada uno de estos elementos arquitectónicos no se debe considerar aislados, ya que forman parte de un proyecto integrador del complejo arquitectónico, por lo tanto; la disposición, la orientación y la función de cada elemento arquitectónico es otro de sus atributos principales del complejo urbano más monumental de Mesoamérica. Figuras núm. 1 y 2. 


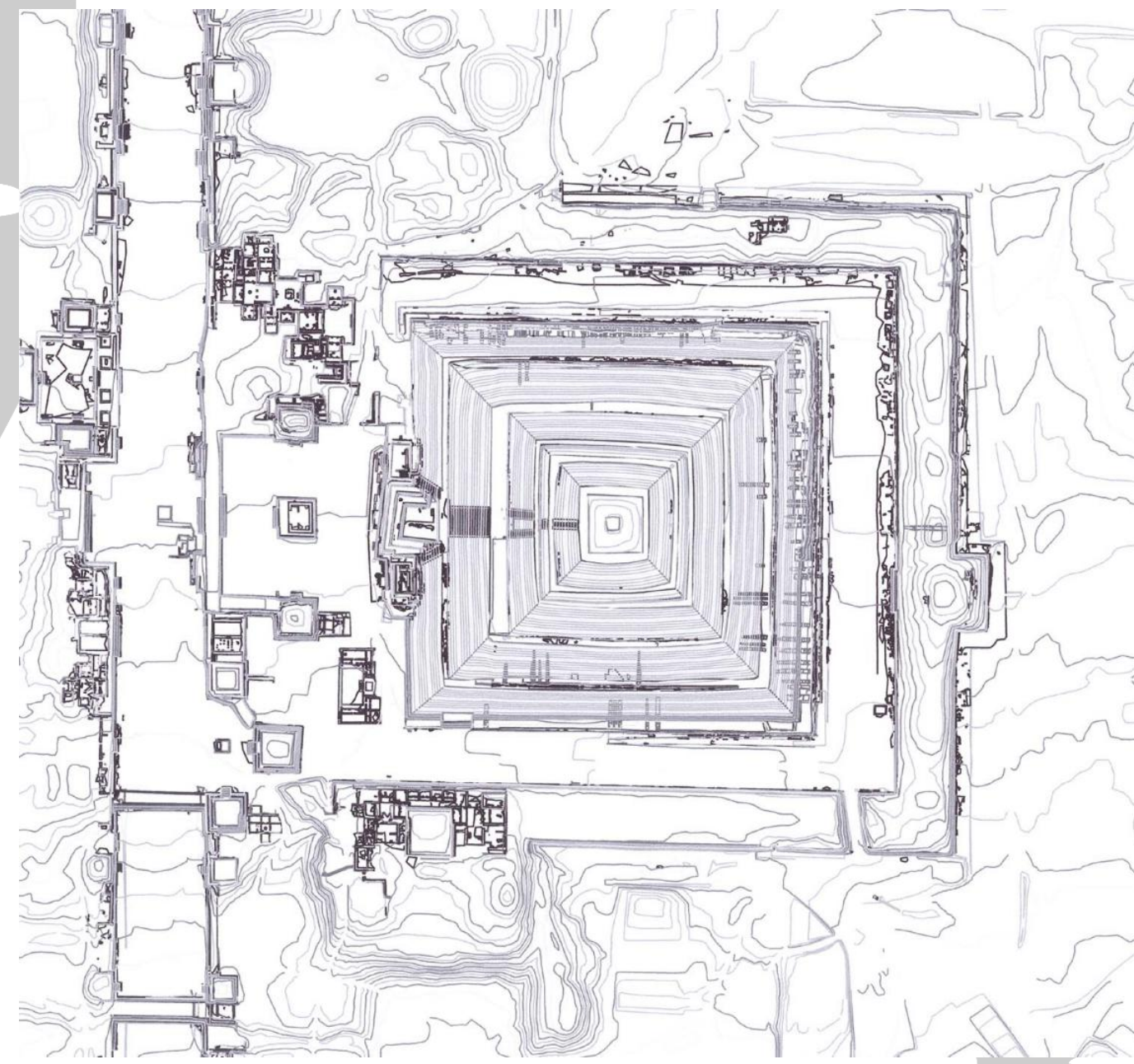

Figura 1. Planta del complejo arquitectónico de la Pirámide del Sol. Proyecto Pirámide del Sol, 2007.

En todos los casos conocidos en Teotihuacán la plataforma piramidal que funciona como el basamento del templo, cuenta justo frente a su fachada principal 
con una amplia plaza abierta y en cuyo espacio central se construye un adoratorio o templo menor, este es un patrón Mesoamericano de templos, patios $\mathrm{y}$ adoratorios muy común en todo su territorio.

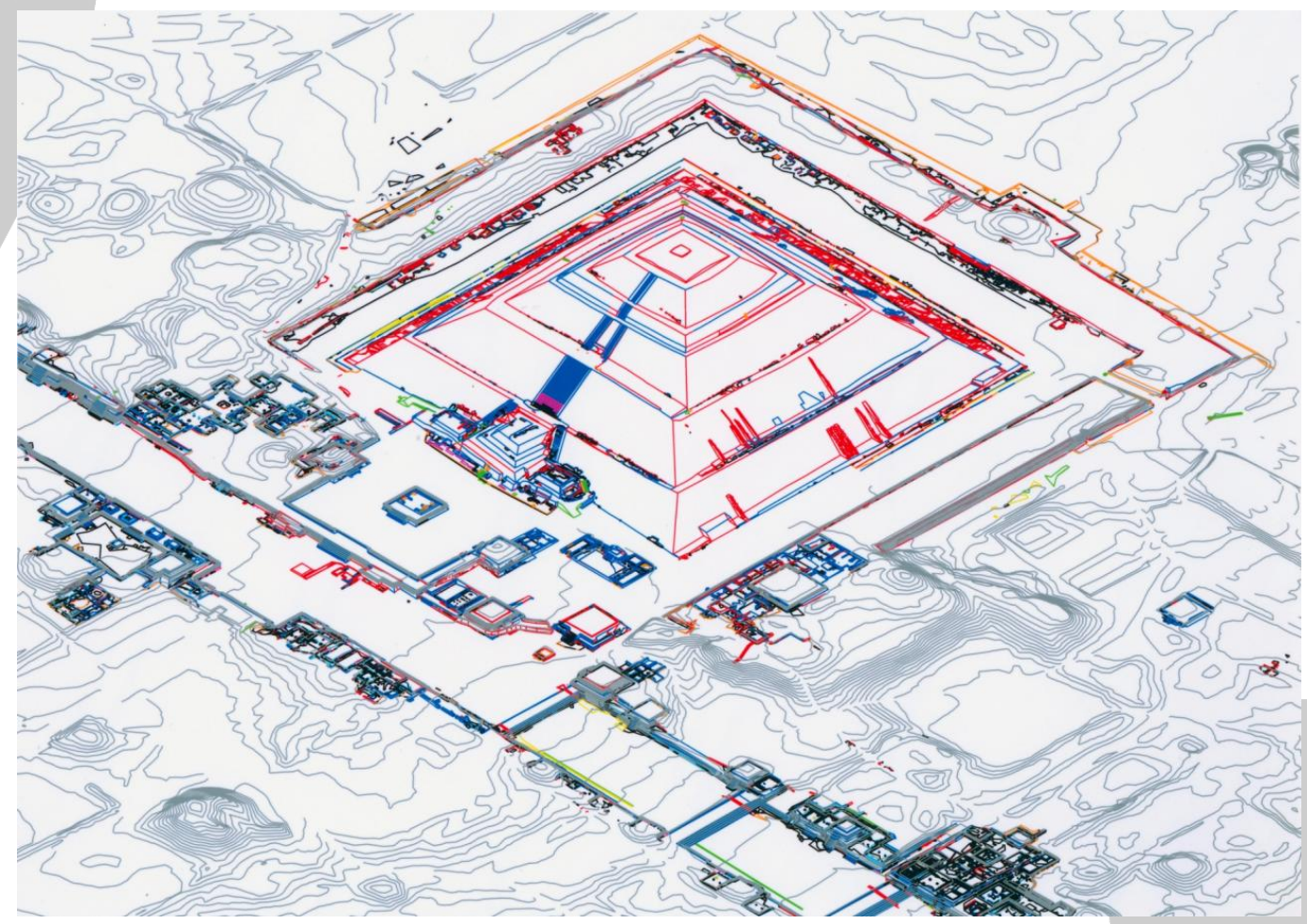

Figura 2. Planta del complejo arquitectónico de la Pirámide del Sol. Proyecto Pirámide del Sol, 2007.

Este complejo arquitectónico funciono como el centro ideológico, religioso y político de la ciudad, resguardando el templo de la deidad tutelar de la ciudad, el dios de la lluvia. Era importante mantenerlo con un acceso restringido, ya que la 
muralla resguarda no solamente al templo principal, al área administrativa y al espacio residencial de los gobernantes.

La construcción de esta unidad urbana dio inicio con la excavación de un túnel en la roca madre para funciones rituales con una profundidad de $6.5 \mathrm{~m}$ y largo de 103 $\mathrm{m}$ se ha calculado que se cavó por completo de forma artífica cerca del siglo uno o dos a. C. Justo sobre este túnel se inicio la construcción de la gran pirámide del Sol a mediados del siglo uno d C. Ver figura núm 3.

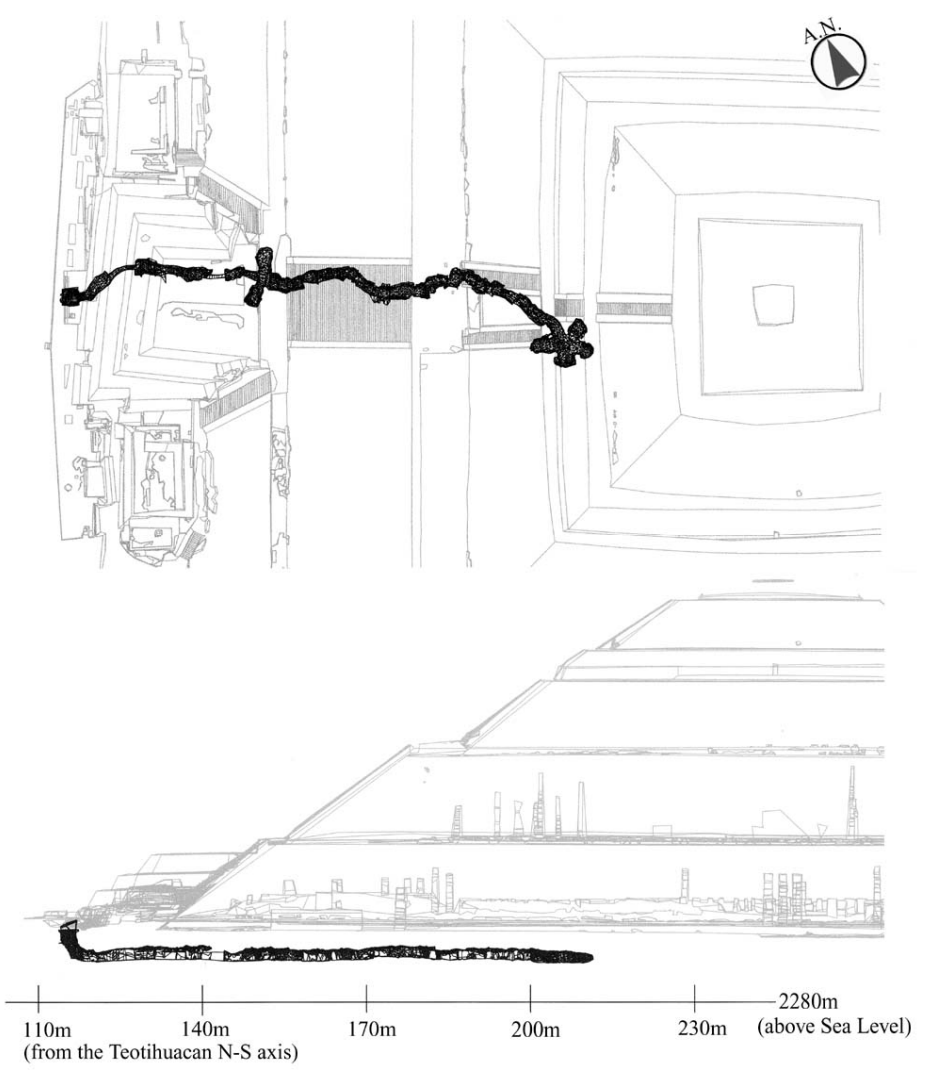

Figura 3. Planta y perfil de la pirámide del Sol con la ubicación del túnel antiguo ubicado bajo la gran pirámide. Levantamiento realizado por los proyectos de la pirámide de la Luna y pirámide del Sol en 2008. 
Como otro atributo relevante de esta unidad urbana está el patrón de ofrendas dedicadas a la construcción o a las deidades del sitio. Este aspecto sin embrago forma parte de un sistema de materialización ideológica típico de Teotihuacán para la construcción de los edificios públicos principales. Para el caso específico de la pirámide del Sol se han registrado en total 29 ofrendas, incluyendo entierros humanos. A continuación se enlistan las ofrendas y los autores:

1. Leopoldo Batres (1905-1906) registró 12 ofrendas que corresponden a restos de infantes en las esquinas del segundo, tercero y cuarto nivel de la pirámide. (Batres 1908). José Pérez y Eduardo Noguera (1933) registran 4 ofrendas en el interior de la pirámide por medio de un túnel horizontal que ellos mismos realizaron ubicado en el centro de la fachada poniente con dirección al centro del edificio: (Noguera, Eduardo 1935. Pérez, José 1935). Las cuatro ofrendas corresponden al interior de la plataforma adosada; La Ofrenda 13, a 5 metros de la entrada del túnel una concentración de 22 piezas de cerámica. La Ofrenda 14, a 11 metros de la entrada del túnel corresponde una concentración de conchas y caracoles cortados. La Ofrenda 15, de 7 objetos ubicada entre 6 y $10 \mathrm{~m}$ de la entrada del túnel. La Ofrenda 16, son 140 piezas completas se registraron entre los 10 y $16 \mathrm{~m}$ de profundidad en el túnel;

2. Millon, Drewitt y Bennyhoff en 1959 Registran 3 ofrendas más: (Millon y Drewitt 1961. Millon, Drewitt y Bennyhoff 1965);

3. La Ofrenda 17 , encontrada a 13 metros de la entrada del túnel de Pérez se registra un vaso de cerámica con la efigie de Tláloc completo y en buenas condiciones. La Ofrenda 18, ubicada a 55 metros de la entrada del túnel de Pérez consiste de objetos de 
obsidiana, incluyendo una figurilla antropomorfa en posición vertical y más de 30 puntas de proyectil miniatura. La Ofrenda 19, a 56 m en el túnel de Pérez contenía 7 navajas de obsidiana en posición vertical;

4. Las exploraciones dirigidas por Eduardo Matos entre 1992-94 registran 4 ofrendas, una en cada esquina del primer cuerpo (Ofrendas 20, 21, 22 y 23) que consisten en algunas vasijas de cerámica, colocadas en pequeñas fosas cavadas en la roca, justo en el arranque de las esquinas de la primera etapa constructiva. (Raúl Barrea Comunicación Personal);

5. Nawa Sugiyama, Saburo Sugiyama y Alejandro Sarabia (208-2011) Registran 6 ofrendas en el interior del túnel de Pérez. (Sugiyama, Nawa; Saburo Sugiyama y Alejandro Sarabia 2013: 403-432);

6. La Ofrenda 24, Corresponde al Entierro 2, ubicado a $106 \mathrm{~m}$ de profundidad en el túnel de Pérez, restos de un individuo perinatal en posición flexionado;

7. La Ofrenda 25, corresponde al entierro 3 ubicado a $110 \mathrm{~m}$ en el túnel de Pérez, y es un cráneo humano;

8. La Ofrenda 26, corresponde al Entierro 4, ubicado a $101 \mathrm{~m}$ en el túnel de Pérez y es un individuo infantil de 6 años de edad;

9. La Ofrenda 27, Corresponde al Entierro 5, y son 2 individuos desarticulados de 35 a 45 años de edad en el relleno de la plataforma adosada, a 3-4 m de la entrada del túnel de Pérez; 
10. La Ofrenda 28, Corresponde a la ofrenda 1 del proyecto Pirámide del Sol, ubicada A $108 \mathrm{~m}$ de profundidad en el túnel de Pérez, compuesta por una concentración de materiales como discos de pizarra, figurillas de obsidiana, puntas de proyectil, y concha;

11. La Ofrenda 29, corresponde a la ofrenda 2 del proyecto Pirámide del Sol, se encuentra a $85 \mathrm{~m}$ de la entrada del túnel de Pérez. consiste en una gran concentración de materiales; una máscara de piedra verde, objetos en obsidiana, concha, discos de pizarra y restos de animales, como jaguares, águilas y serpientes.

Todas estas ofrendas son producto de rituales de sacrificios humanos o de animales sagrados para la consagración del monumento dedicado a la deidad de la lluvia y al ritual del nuevo ciclo.

Con las exploraciones en la base de la pirámide en la temporada 2009 y 2010 se pudo registrar seis pequeñas ofrendas colocadas en el momento de iniciar la construcción, sobre o cerca de la roca natural y cerca del centro arquitectónico, es necesario aclarar que a diferencia de las ofrendas de la Pirámide de la Luna y de la Serpiente Emplumada, las ofrendas de fundación en donde se encuentran exactamente en el centro del edificio o en los ejes arquitectónicos, las de la Pirámide del Sol se ubican ligeramente desviadas al oeste, y es que de esta manera su ubicación coincide con el fondo del túnel antiguo (también conocido como "cueva ceremonial"), dando un significado especial a la construcción de la pirámide y a la ubicación en el sistema urbano. 
En estas excavaciones se identificaron restos arquitectónicos anteriores a los que se ven actualmente del edificio, así como evidencia de un ritual de terminación que ocurrió directamente sobre un piso de la fase pre-Pirámide del Sol, un entierro de infante nonato en un nivel anterior a esa estructura, sugiriendo el culto a la deidad de la lluvia. (Sugiyama, Nawa et. al. 213:412-415).

La ofrenda 1 fue depositada en el relleno de la pirámide, cubriendo la subestructura de la fase pre-Pirámide, que fue destruida. Esta ofrenda incluye piezas trabajadas de obsidiana como navajillas, puntas de proyectil y figurillas, un disco de pirita, un caracol marino grande y muchos fragmentos de material orgânico, (Sugiyama, Nawa, et. al. 213:416-17).

\section{La decoración arquitectónica}

La decoración de la plataforma adosada central se puede entender con esculturas en bulto de felinos, ubicados tanto en el tablero de los cuatro cuerpos, o bien sobre los pisos entre los niveles arquitectónicos. A juzgar por la variedad en la forma general de las esculturas tanto como en los rasgos funcionales de las mismas, se puede ínferos cuando menos cuatro programas escultóricos para la plataforma adosada. No ha sido posible por el momento determinar la secuencia de estos programas decorativos, ni su relación con la secuencia arquitectónica que le sirvió de base. 
Resulta que es escasa la evidencia al respecto, pero que si permiten inferir algunos datos como suponer que la plataforma adosada central mostro una decoración con esculturas similar al del Templo de la Serpiente Emplumada en la Ciudadela, claro con diseños de felinos saliendo de los tableros, o bien con esculturas de felinos saliendo de los pisos entre los cuatro cuerpos (Sarabia, A. 2016:17) De cualquier manera la fachada de la gran Pirámide mostro una vista general muy diferente a como se muestra hoy día. Ver figura núm 4.

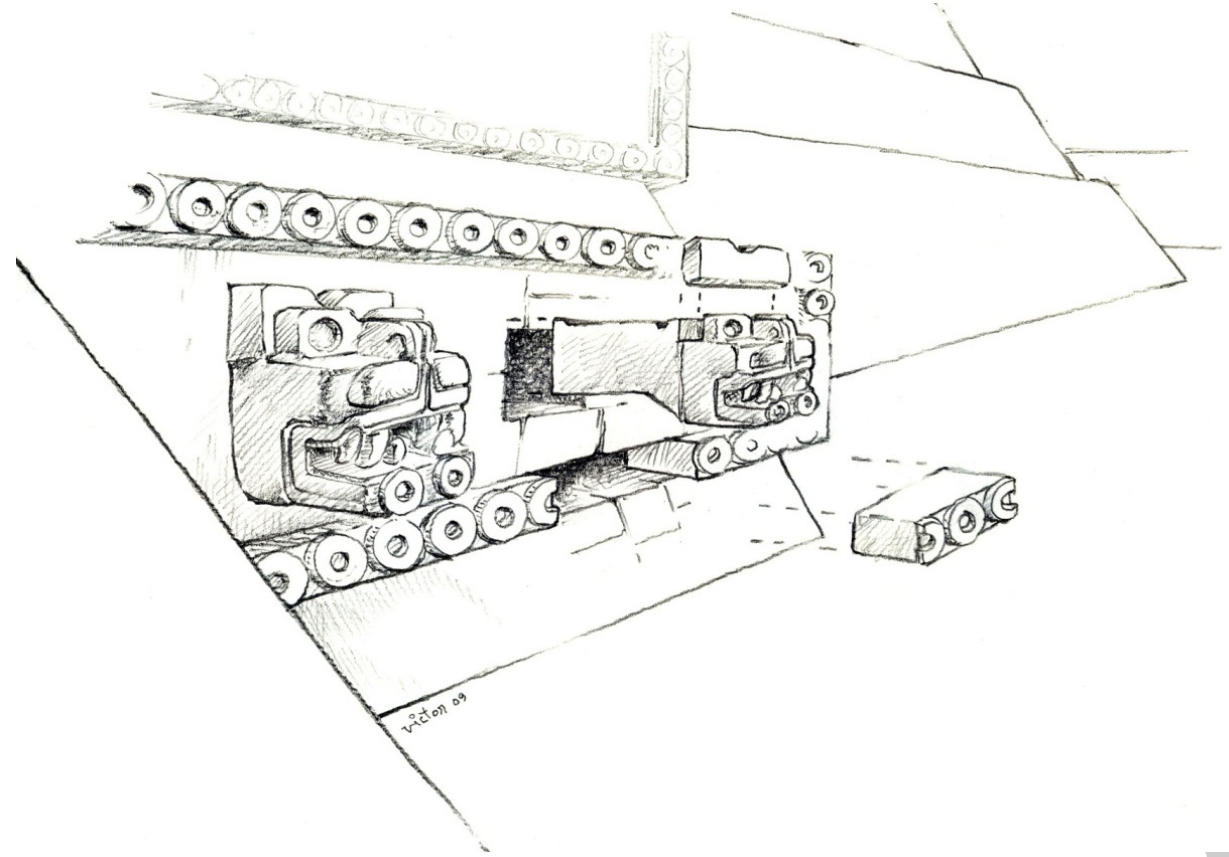

Figura 4. Reconstrucción hipotética de la decoración de la pirámide del Sol a la plataforma adosada en uno de sus programas escultóricos. (Víctor Álvarez y Alejandro Sarabia 2011). 
Se han registrado en total 318 esculturas en rocas de andesita, riolita, basaltos y piedras verdes, entre los que se cuentan 22 canales y registros, 18 bloques tallados sin decoración, 45 bloques con decoración en bajo relieve, 56 bloques con el relieve de círculos que funcionaron como molduras en los tableros, 94 bloques que formaron parte de paneles o esculturas armables en secciones de diferentes tamaños (en este grupo incluimos 14 cabezas de felinos, 11 garras de felinos en bulto, 9 representaciones de corazones humanos, 3 garras de felino en relieve, etc.).

Incluimos en el grupo de esculturas a 8 mascaras de piedra verde, 14 almenas o placas con la representación de atados quemados, 9 monolitos de piedra verde, 3 representaciones del dios viejo del fuego y tres del monstruo de la tierra en esculturas en bulto. Se registran varios fragmentos de esculturas que no permiten saber el diseño general (Sarabia 2017).

Aunque la decoración de la plataforma adosada fue la representación de procesiones de felinos comiendo corazones humanos, el resto de las esculturas se usaron no tanto como elementos arquitectónicos, sino como objetos aislados fijos, ubicados tanto en la cúspide, como en los cuatro diferentes niveles arquitectónicos. 

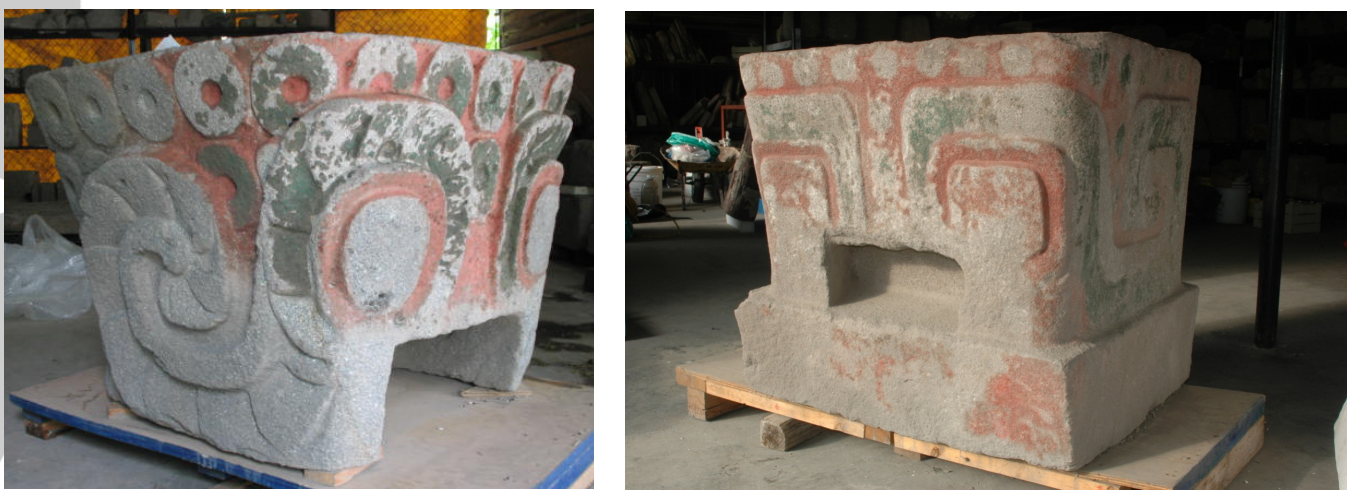

Figuras 5 y 6 .Escultura de andesita. La forma general que representa un "monstruo" con grandes ojos redondos enmarcado con "plumas", las orejas en espiral y con una serie de (42) círculos en relieve en el rostro y en la parte posterior. La "boca" abierta con forma rectangular en el eje de la pieza y por debajo de los ojos, no muestra nariz ni mandíbula. La pieza parece estar completa, pero formó parte de un mosaico mayor.

Desde las exploraciones de Batres que dieron inicio en 1905; Castañeda 1946; Bastien en 1947; Chadwicken 1962-4; Contreras en 1962-4; Acosta en 1966; Matos en 1992-4; Cabrera 2000; y Sarabia 2005-2010, todos han registrado esculturas y bloques de la arquitectura que decoraba la fachada de la plataforma adosada o de la gran pirámide, en lo que respecta a esculturas en las temporada 2009 y 2012 se registró las única escultura "in situ” en todo el complejo arquitectónico (Sarabia 2017) en tanto Batres en 1905 y Sarabia en 2010 y 2012 liberaron algunos elementos arquitectónicos "in situ”, que consisten en taludes y molduras de tableros. Fue Acosta quien liberará el desplante de la escalinata original de la plataforma adosada central en 1966 (Acosta 1970). 
Solamente en 30 casos se cuenta con esculturas completas, ya que a juzgar por los diferentes programas escultóricos, la mayoría forman conjuntos o paneles en relieve, similares a los trabajados en el templo de la Serpiente Emplumada:

1. Un gran brasero registrado por Batres sobre la Plataforma Adosada Central;

2. dos esculturas de cráneos humanos reportados por Batres;

3. dos grandes crótalos de cascabel en la base de la Plataforma Adosada reportados en 1946 por Castañeda (Bastien 1947), son por cierto las esculturas más grandes conocidas de este complejo; un crótalo más por Chadwick en 1964 de menores dimensiones;

4. una cabeza de felino registrada por Matos; tres esculturas del monstruo de la tierra registradas por Sarabia dos almenas registradas por Batres y una registrada por Sarabia;

5. 9 estelas de piedra verde, dos registradas por Cabrera y cuatro por Sarabia, dos más por Matos;

6. y una escultura que representa al atado de años reportada por Batres, entre otros. 


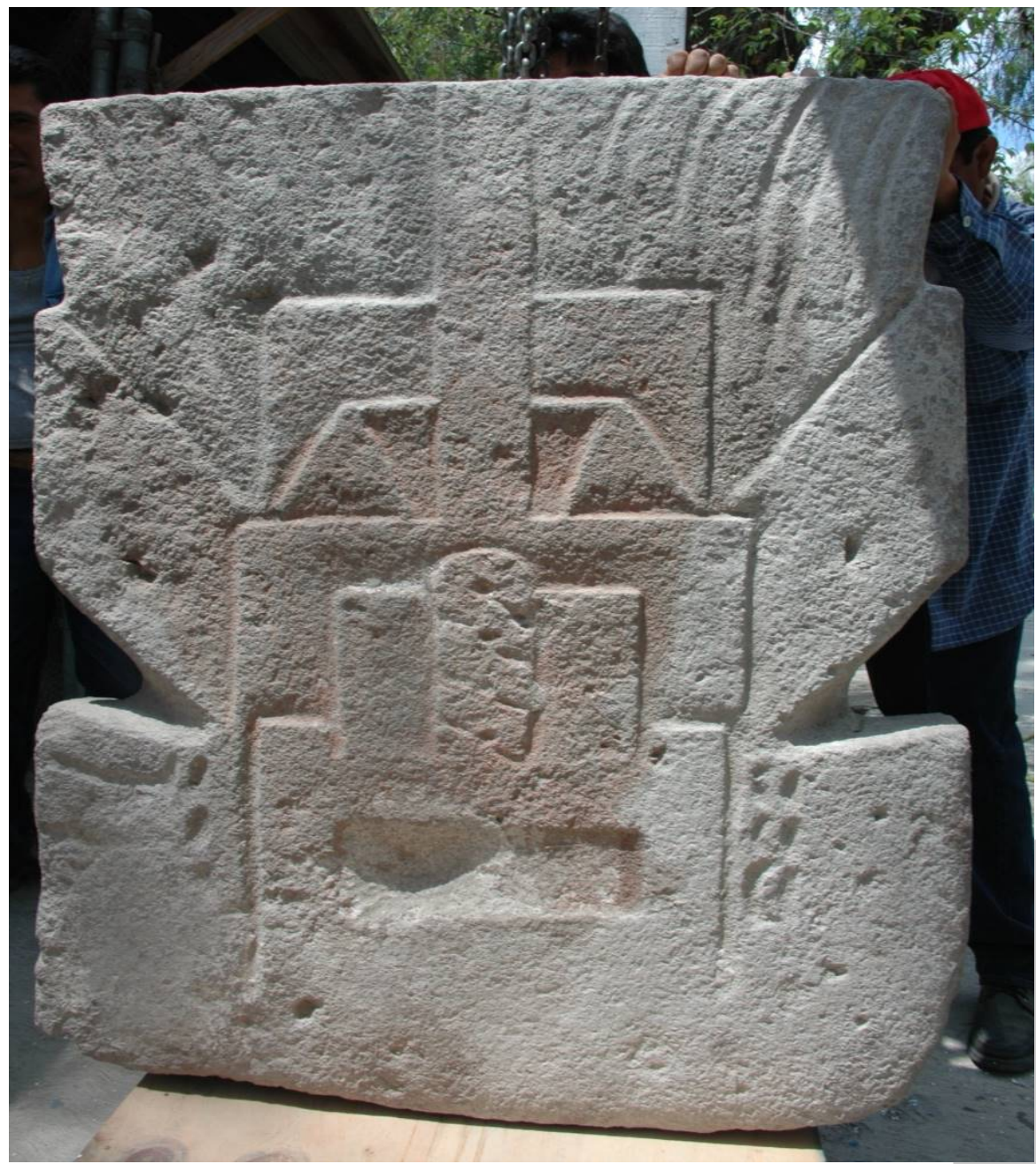

Figura 7. Placa escupida en andesita con un diseño en bajo relieve que representa el atado de años en la ceremonia del fuego nuevo. Este grupo de esculturas se han registrado en Teotihuacán solamente en la pirámide del Sol. 


\section{REFERENCIAS BIBLIOGRÁFICAS}

Acosta, Jorge. (1970) "Las exploraciones arqueológicas en Teotihuacán" Teotihuacan lugar de Dioses: 5-10 Artes de México No. 134. Año XVII.

Bastien, Remi. (1947) La Pirámide del Sol en Teotihuacán. Tesis profesional, ENAH: México.

Batres, Leopoldo. (1908) Teotihuacán: Memoria que presenta al XV Congreso Internacional de Americanistas en Quebec, Canadá (1906) Imprenta Fidencio Soria. México, D.F.

Chadwick, Robert. (1964 a) "Zona 5-B. dieciochoavo informe mensual del $1^{o}$ al 31 de marzo de 1964" mecanoscrito del Proyecto Teotihuacán, Temporada V. Archivo Técnico del INAH.

Chadwick, Robert. (1964 b) "Zona 5-B. Excavación y reconstrucción de la Plaza de la Pirámide del Sol, 1963-1964" mecanoscrito del Proyecto Teotihuacán, INAH. Archivo Técnico del INAH.

Contreras, Eduardo. (1964 a) "Zona 5-A. Dieciochoavo informe mensual del $1^{\circ}$ al 31 de marzo de 1964" mecanoscrito del Proyecto Teotihuacán Temporada V. Archivo Técnico del INAH.

Contreras, Eduardo. (1964b) "Zona 5-A Informe final de los trabajos desarrollados en la zona durante el periodo entre ell6 de enero de 1963 y el 15 de agosto de 1964", mecanoscrito del Proyecto Teotihuacán, temporada V 1963-1964. Archivo Técnico del INAH.

Millon, René y Bruce Drewitt. 1961. Earlier Structures within the Pyramid of the Sun at Teotihuacán. American Antiquity 26, 3, part. 1:371-380. Salt Lake City.

Millon, René;; B. Drewitt; J.A. Bennyhoff. (1965) The Pyramid of the Sun at Teotihuacán: 1959 Investigations. In Transactions of the American Philosophical Society, New series, vo1.55, Part 6. The American Philosophical Society, Philadelphia. 
Noguera, Eduardo. 1935. Antecedentes y relaciones de la cultura teotihuacana. El México Antiguo. México, abril 1935, tomo III, números 5-8, págs.3-89.

Pérez, José. 1935. Exploración del túnel de la Pirámide del Sol. El, México Antiguo. México, abril 1935, tomo III, números 5-8: 91-95.

Sarabia González, Alejandro. 2016. Programa de Conservación e Investigación en el Complejo Arquitectónico de la Pirámide del Sol., Teotihuacán, México. propuesta de trabajo. Archivo Técnico de la Coordinación Nacional de Arqueología.

Sarabia González, Alejandro. 2017. Programa de Conservación e Investigación en el Complejo Arquitectónico de la Pirámide del Sol., Teotihuacán, México. Informe de trabajo.Coordinación Nacional de Arqueología.

Sugiyama, Nawa; Saburo Sugiyama y Alejandro Sarabia 2013. Inside the Sun Pyramid at Teotihuacán, México: 2008-2011 excavations and preliminary results. Latin American Antiquity. 24 (4) pp. 403-432. 